\title{
INTERCOOPERAÇÃO EM UMA REDE DE COOPERATIVAS AGROALIMENTARES DA CADEIA DO LEITE NO PARANÁ
}

\author{
Heitor José Cademartori Mendina* \\ José Jerônimo de Menezes Lima** \\ Lasier Gorziza de Souza*** \\ Gabriel Sperandio Milan*****
}

RESUMO: O foco do estudo foi o de analisar fatores impulsionadores e restritivos associados às ações de intercooperação. Para tanto, o estudo trata de pesquisa qualitativa, baseada em estudo de caso único, realizada em uma rede de cooperativas agroalimentares da indústria do leite do Estado do Paraná, Brasil. A pesquisa considerou como pressuposto teórico que a intercooperação pode ser uma estratégia de criação de vantagem competitiva para que redes de cooperativas possam sobreviver e crescer em seus mercados de atuação. Os dados foram coletados em entrevistas com os gestores da rede estudada, sendo tratados por meio de análise de conteúdo e posterior triangulação dos dados. Foi constatado que há fatores que influenciam a intercooperação e concorrem para obtenção de resultados positivos ou negativos, dependendo de como são gerenciados. Os principais fatores impulsionadores da intercooperação identificados foram: prestação de serviços de recebimento, beneficiamento e industrialização da matéria- prima, marca forte de parceiros, tomada de decisão colegiada, coparticipação societária das cooperativas da rede entre si, unidades de negócios independentes, comercialização centralizada e parceria com empresas internacionais renomadas. Os principais fatores restritivos à intercooperação destacados foram: parcerias equivocadas e concorrência entre as cooperativas associadas à rede. No caso estudado, o impacto gerado pelos fatores restritivos à intercooperação foi devidamente gerenciado, especialmente no que diz respeito à governança è à gestão da rede.

PALAVRAS-CHAVE: Cooperação; Cooperativas; Estratégia; Governança de redes; Intercooperação; Redes de cooperativas.

\footnotetext{
"Doutor em Administração pela Universidade do Vale do Rio dos Sinos - UNISINOS. Docente e pesquisador da Escola Técnica de Cooperativismo - ESCOOP, Brasil.

** Doutor em Administração pela Universidade do Vale do Rio dos Sinos - UNISINOS. Docente e pesquisador pela UNISINOS.

**** Doutor em Administração pela Universidade do Vale do Rio dos Sinos - UNISINOS. Pós-doutamento em Engenharia de Produção. Professor e pesquisador da Universidade Federal de Santa Maria - UFSM, Brasil.

***** Doutor em Engenharia de Produção pela Universidade Federal do Rio Grande do Sul - UFRGS. Docente e pesquisador da Universidade de Caxias do Sul - UCS, Brasil. E-mail: gsmilan@ucs.br
} 


\title{
INTERCOOPERATION OF AN AGRICULTURE-FOOD COOP NET WORK WITHIN THE MILK CHAIN IN THE STATE OF PARANÁ
}

\begin{abstract}
Current paper focuses on triggering and restrictive factors associated to inter-cooperation activities. The study deals with a qualitative research, based on a single case study, undertaken in a network of agro-food coops of the dairy industry in the state of Paraná, Brazil. The theoretical presuppositions deal with inter-cooperation as a strategy in competitive advantage so that coop networks may survive and grow. Data were collected from interviews with administrators of the network under analysis and treated by content analysis and data triangulation. There are factors that influence inter-cooperation and compete for positive or negative results, depending on how they are administered. The main triggering factors of inter-cooperation comprises receiving services, improvement and industrialization of prime matter, strong trademark of the other companies, collegiate decision-taking, societal co-participation of the network coops among themselves, independent business units, centralized commercialization and joint ventures with relevant international firms. The main restrictive factors to inter-cooperation are dubious joint ventures and competitions between coops associated to the network. In the case of the coop under analysis, the impact generated by restrictive factors to inter-cooperation was duly administered, especially with regard to governance and network administration.
\end{abstract}

KEY WORDS: Cooperation; Coops; Strategy; Network administration; Inter-cooperation; Coop network.

\section{INTRODUÇÃO}

Nesta pesquisa, foi adotado o conceito proposto por Lago e Silva (2011), que consideram a intercooperação como possível de ser encontrada em quaisquer manifestações de ajuda mútua que normalmente surgem em situações de adversidade, quando existe a necessidade de apoio recíproco entre os parceiros (ou envolvidos), tanto para sobreviver, quanto para competir de maneira mais eficaz. Inclusive, Balestrin e Verschoore (2016) enfatizam que a garantia de cooperar é saber que futuramente haverá cooperação recíproca, e sugerem que a colaboração não está associada à pressão hierárquica ou do mercado, mas traz em si a complexidade dos atores multidimensionais que são, ao mesmo tempo, integrantes 
e representantes de diversas manifestações coletivas envolvidas e relacionadas pelas relações interorganizacionais que têm fronteiras sobrepostas e difusas.

No âmbito do associativismo, Schneider (2010, p. 41) afirma que "[...] cooperativa é uma associação autônoma de pessoas que se unem voluntariamente para satisfazer aspirações e necessidades econômicas, sociais e culturais comuns, por meio de uma empresa de propriedade coletiva e democraticamente gerida". Uma rede é um tipo específico de relação que liga pessoas, objetos e/ou eventos, aplicando-se aos atores, artefatos sociais e equipes, agindo em eventos específicos (MITCHELL, 1985). Negócios em redes são aqueles que conectam relações entre atores que controlam atividades em torno de um negócio, podendo ser vistos, nesta modalidade, como a união de recursos entre diferentes organizações, ou como a integração e a coordenação de relacionamentos econômicos ou não econômicos, interna ou externamente às organizações envolvidas. Especificamente, redes horizontais são aquelas que possuem dimensão cooperativa e são formadas por empresas que guardam sua independência, mas que, entretanto, optam por desenvolver algumas atividades de forma conjunta com objetivos comuns entre si, mas sem privar as relações estratégicas de seus membros (TODEVA, 2006).

Para Pedrosa Ortega e Hernández Ortiz (2011), há um crescente interesse sobre cooperativas agroalimentares, devido à sua importância para a estrutura empresarial de qualquer país, uma vez que dinamizam zonas rurais, criam empregos e fixam populações em seus territórios. Justifica-se, então, a escolha do segmento de cooperativas por considerar que este estudo agrega contribuições que podem ajudar gestores de redes de cooperativas em atividades relacionadas à gestão da intercooperação.

Neste contexto, a maioria das cooperativas agroalimentares apresenta o problema da constância do líder carismático fundador, que enfrenta dificuldades tanto para desempenhar funções, como para delegá-las, e mais ainda no processo sucessório. Este líder normalmente se caracteriza por permanecer por período de tempo muito longo no poder (MENDINA, 2015), o que pode repercutir negativamente na perda de competitividade (CRÚZIO, 2005; MORAIS et al., 2011). E tais considerações levam a um debate sobre intercooperação em redes horizontais, que passa pela clara definição da forma de governança e de gestão da rede, uma vez que determina 
sua estrutura e seu modus operandi. É a partir dos mecanismos de governança e de gestão definidos e implementados que a rede estabelece estratégias de cooperação transparentes e em consenso que norteiam as ações que devem ser realizadas pelos seus membros (MENDINA, 2015).

Em relação à produção de leite, de acordo com o IBGE - Instituto Brasileiro de Geografia e Estatística, em ranking divulgado em 2016, o Paraná ultrapassou o Rio Grande do Sul, o segundo maior produtor de leite do país. Conforme os dados informados, o Paraná produziu 4,66 bilhões de litros de leite em 2015. Cerca de 60 milhões de litros a mais que o Rio Grande do Sul, que produziu 4,59 bilhões de litros de leite no mesmo período. Minas Gerais, por sua vez, continua sendo o maior Estado produtor de leite do Brasil, alcançando 9,14 bilhões de litros de leite produzidos em 2015 (IBGE, 2016). Estes dados tendem a ser mais representativos com a projeção de formação de redes de intercooperação para melhor aproveitamento dos fatores impulsionadores e minimização dos fatores restritivos das redes existentes nestes três Estados brasileiros, ainda mais através de uma adequada gestão e governança.

Dessa forma, o objetivo do estudo foi o de analisar fatores impulsionadores, os quais incentivam as cooperativas a promover ações de intercooperação em prol da rede ou de si mesmas; e fatores restritivos, que as limitam ou as impedem de realizar ações de intercooperação, considerando-se cooperativas agroalimentares atuando em rede horizontal na cadeia do leite no Estado do Paraná.

\subsection{REVISÃO DE LITERATURA}

\subsubsection{Cooperativismo}

O cooperativismo pode ser considerado como uma das poucas doutrinas econômicas que nasceram diretamente da prática de trabalhadores. Dessa forma, os trabalhadores materializam o associativismo com seus próprios esforços e ajuda recíproca, coordenando a organização de recursos econômicos coletivos com a finalidade de alcançar a saciedade de suas carências. O cooperativismo apresenta a proposta de uma organização diferente, em que cada membro pode inferir, ou 
interferir, diretamente no destino do empreendimento cooperado, de acordo com o princípio de que cada cooperado tem o direito a um único voto (CARVALHO, 2011).

Por conseguinte, o cooperativismo também se fundamenta na ideia de economia solidária (MORAIS et al., 2011), fortalecendo a atuação do homem do campo, agregando valor às suas atividades e aos seus produtos, servindo, inclusive, como uma alternativa socioeconômica para a geração de renda no campo e para o próprio desenvolvimento do país (LECHAT, 2008; MORAIS; LANZA, 2010).

O cooperativismo, no que tange à estratégia, pode se utilizar da intercooperação para alavancar negócios com distintos vieses. Contudo, com o cuidado de não perder o rumo que melhor o auxilia, ou seja, a vinculação com o universo negocial, que viabiliza o fortalecimento de organizações que participam e que competem em redes, consolidando a sua estrutura competitiva e potencializando os seus recursos e os recursos dos parceiros em prol de objetivos mútuos. O cooperativismo, por sua versatilidade, portanto, apresenta-se como elemento facilitador de transações, pode criar valor, possibilitando que a organização cooperativa se distinga dos demais competidores, construindo possíveis vantagens competitivas ou ganhos em qualidade (PORTER, 1990). Além disso, possui alto poder adaptativo, sem perder o seu caráter social, constituindo-se em vantagem e em grande diferença entre cooperativas e empresas tradicionais (PALACIO; CLIMENT, 2007).

Segundo Triguero-Cano e Cuerva Narro (2011), muitas vezes, o caminho estratégico pode se apresentar no campo da inovação tecnológica, como se observa no segmento de cooperativas agroalimentares, as quais vêm investindo em tecnologia nas fases de produção e de transformação de seus produtos, em Pesquisa e Desenvolvimento (P\&D) e em valores intangíveis. Até então, tais investimentos eram apenas para empresas de grande porte, capitalistas, visto que abarcavam a grande fatia de incentivos fiscais governamentais, absorviam possíveis riscos econômicos, tinham facilidade de acesso ao capital disponível para este tipo de investimento e possuíam maior capacidade de economias de escala (TRIGUEROCANO; CUERVA NARRO, 2011). 


\subsubsection{Intercooperação}

Em relação à intercooperação, Park e Ungson (2001) afirmam que, quando duas partes intercooperam, é preciso investir tempo e esforços suficientes e simétricos, mesmo que em período de atuação conjunta temporário. As partes sabem que se os esforços de ambos forem assimétricos ou insuficientes pode ocorrer comportamento oportunista pela sonegação de informações ou a provisão de informações falsas que levam ao fracasso da iniciativa. A intercooperação, que além de ser um dos princípios das estruturas cooperativas, pode ser utilizada como estratégia de ação para obtenção de possíveis vantagens competitivas.

Com a estratégia de intercooperação, alguns resultados podem ser esperados, tais como o aumento das forças internas da cooperativa, as economias externas, o surgimento de sinergias, o efeito de aprendizagem, o que surge a partir do contato entre os associados e suas diretorias entre as cooperativas, no intento de atingir ou de aumentar o poder de escala na utilização de unidades fabris e de seus recursos, inovação e tecnologia, melhoria de gestão e de governança, bem como redução de riscos nos investimentos (BIALOSKORSKI NETO, 2016).

Qualquer relação entre cooperativas, entre associados e cooperativas, ou ainda, entre colaboradores e cooperativas, pode ser vista como intercooperação (LEITE, 1982). E este tipo de relação reforça não somente o cooperativismo, mas também as propriedades coletivas e a economia solidária (MORAIS; LANZA, 2010; MORAIS et al., 2011). Para Bialoskorski Neto (2016), a manutenção da eficácia produtiva, social e dos níveis de possíveis vantagens competitivas somente será alcançada pelo sistema de cooperativismo com uma gestão forte, além de outros fatores impulsionadores, pois as cooperativas estão sendo impelidas a se adequarem ao mercado, tendo como foco as aspirações dos consumidores. Porém, o debate a respeito da gestão de cooperativas destaca que, nestas sociedades, os sócios têm participação democrática, que pode ser limitada e complexa, o que pode não contribuir para a sua eficácia (DAVIS; BIALOSKORSKI NETO, 2010).

Muitas iniciativas cooperativistas fracassam, o que se pode traduzir que há problemas. No Brasil, a discussão sobre o tema, que está incluído em governança corporativa, é muito incipiente. No que tange à governança corporativa 
para cooperativas, é mais recente ainda. Somente em 2006 é que a Organização das Cooperativas Brasileiras (OCB) sintetizou um documento básico de referência na área (DAVIS; BIALOSKORSKI NETO, 2010).

Davis e Bialoskorski Neto (2010) ressaltam que as organizações cooperativas normalmente têm um número elevado de associados, expressando semelhança com algumas funções públicas, o que permite traçar um paralelo entre gestão de cooperativas e administração pública. Logo, o processo de desregulamentação é o sintoma de que o poder público é inapto para atingir seus objetivos de prestação de serviços em mercados. Na mesma proporção, as cooperativas apresentam tais sintomas quando são ineficientes em fazer frente à competição nos mercados em que atuam. Também a legitimidade da afiliação que dá aos sócios a condição de proprietários assegura que, muitas vezes, os líderes eleitos construam suas próprias políticas (DAVIS; BIALOSKORSKI NETO, 2010).

Os associados de cooperativas podem contratar gestores para exercer cargos administrativos dentro das cooperativas, o que pode confrontar com o interesse dos associados, os quais também são donos, provocando um choque de gestão. Para alcançar êxito na gestão, é necessário que, caso exista, o Conselho de Administração seja eficiente e que conte com membros bem preparados, ou seja, com boa formação e experiência de mercado. Para tanto, os conselheiros deveriam ser escolhidos também por sua qualificação, fato que geralmente não ocorre no Brasil, que não aceita a adesão de membros no Conselho Fiscal que não sejam associados da cooperativa e a função da direção executiva da cooperativa é feita por um presidente associado. Tal situação é diferente em muitos países, onde a gestão é realizada por profissionais competentes contratados (MARTI; IGUAL, 2008). No Brasil, em alguns casos, pode-se encontrar um superintendente profissional contratado para realizar a gestão operacional da cooperativa, mas os demais cargos são ocupados por sócios das cooperativas, invariavelmente.

O desenvolvimento da intercooperação se dá, de fato, pelo desdobramento e pela operacionalização das estratégias estabelecidas por parte da rede, por meio da realização de ações pautadas em responsabilidades e em benefícios recíprocos em busca de vantagens competitivas para a própria rede e para os agentes que dela participam, maximizando o capital social criado em tal contexto. Por outro lado, a 
forma como a rede e seus membros se comportam em seu contexto de atuação, ao longo do tempo, em termos de resguardar as alianças e a confiança estabelecidas, impacta sobremaneira na reputação que influencia diretamente na imagem, nas relações entre os agentes envolvidos e no desempenho deles e da rede como um todo. Quando os membros da rede percebem oportunidades que individualmente não conseguiriam alcançar, podem reunir os recursos necessários, de forma individual, ou com parceiros, para aproveitá-las, favorecendo a sobrevivência e o crescimento, que são objetivos de qualquer organização (PORTER, 1990).

Particularmente no caso de redes de cooperativas agroalimentares atuando em rede horizontal, a questão da internacionalização está diretamente ligada às oportunidades de mercado, quando emergem, o que também pode trazer vantagens competitivas (PEDROSA ORTEGA; HERNÁNDEZ ORTIZ, 2011; TRIGUERO-CANO; CUERVA NARRO, 2011), como se observa no caso da Cooperativa de Mondragón, na Espanha.

\subsubsection{Governança em Redes}

A governança em redes é um sistema de segunda ordem que não implica a substituição do sistema de governança das empresas participantes da rede, mas que significa que um novo nível de governança é adicionado. Ou seja, cada empresa individualmente mantém o seu sistema de governança, embora quando se remeta às questões de interesse da rede, deva se submeter ao sistema de governança vigente para a rede. O sistema resultante, neste caso, o sistema de governança da rede, é criado pelas próprias empresas que formam a rede, a fim de influenciar os gestores das empresas participantes a agir de maneira que concorram para os objetivos da rede (ALBERS, 2005). Assim, a governança é a chave do sucesso no que se refere às redes, o que é possível verificar quando se foca a questão de desenvolvimento regional, podendo, ainda, servir de possíveis fontes de vantagens competitivas, em termos de eficiência e de flexibilidade das redes (PIORE; SABEL, 1984; PYKE; SENGBERG, 1992).

Por sua vez, a autogovernança é um sistema típico de governança em redes com um pequeno número de integrantes, como um mecanismo eficaz na medida em 
que as tarefas são realizadas pelos próprios empresários, sem a necessidade de uma estrutura autônoma. Como desvantagem, os participantes dividem suas atividades entre a gestão e a governança da rede e a sua própria empresa, com o risco de serem relegadas para segundo plano as questões de gestão da rede ou de suas próprias empresas, podendo surgir conflitos de interesse entre os atores, no que concerne às suas empresas e funções desempenhadas na rede. Com o crescimento no número de participantes, isso pode ocasionar transtornos na gestão de um número maior de envolvidos em interesses que demandem consenso (PROVAN; KENIS, 2007).

Provan e Kenis (2007) e Venkatraman e Chi-Hyon (2004) ressaltam que a governança é a base que limita e estabelece parâmetros para os moldes de participação para cada membro da rede, sendo utilizada com mais frequência em pequenas redes de maneira informal. Os custos de transação também estão diretamente ligados a uma adequada governança, bem como a localização e o relacionamento entre parceiros inerentes à rede. As redes podem ser consideradas como ótimas formas para se reduzir a incerteza e os riscos intrínsecos às transações da empresa em seu ambiente (WILLIAMSON, 1985; 1993). Todavia, deve-se ter em mente algumas barreiras à implementação de práticas de governança apropriadas em redes: conflito com os interesses dos gestores, hostilidades culturais dos gestores às denúncias de práticas questionáveis, falta de compreensão dos bons processos e das boas práticas envolvendo os conselheiros, custos de implementação e diferenças entre os regimes regulatórios adotados pelos países (ANDRADE; ROSSETTI, 2009).

É relevante salientar que a ausência de autoridade tácita de uma empresa que participa de uma rede se caracteriza pela permanência da autonomia geral da empresa e pela sua não submissão a uma autoridade central da rede. Tal reflexão se faz importante uma vez que as empresas são, ao mesmo tempo, governantes e governadas, gerando um processo decisório da rede baseado na negociação e na busca de consenso entre as empresas participantes (ALBERS, 2005; CRÚZIO, 2005). Por isso, o processo de crescimento de uma rede de empresas requer a adequação de uma estrutura organizacional, com seus mecanismos de governança e suas práticas de gestão, de maneira a comportar o maior número de participantes e de volume de negócios e, paralelamente, evitar a perda do caráter cooperativo da rede, quando se trata de redes horizontais que não apresentam uma empresa líder (WEGNER; 
PADULA, 2011). É oportuno enfatizar que quanto mais complexas as redes se tornam, mais difícil é, ou será, administrá-las (HAGE; ALTER, 1997; BALESTRIN; VERSCHOORE, 2016).

\section{MATERIAL E MÉTODOS}

O estudo foi implementado por meio de uma pesquisa qualitativa (REMLER; VAN RYZIN, 2011), baseada em estudo de caso único (YIN, 2014), realizado em uma rede de cooperativas agroalimentares da indústria do leite do Estado do Paraná. A rede analisada é um caso bem sucedido de intercooperação informal em rede de cooperativas agroalimentares, a qual é formada por três cooperativas singulares (Cooperativas A, B e C) e uma Fundação (Fundação ABC). Os dados foram coletados a partir de entrevistas individuais em profundidade, com uma abordagem semiestruturada, mediante a utilização de um roteiro básico de questões (RIBEIRO; MILAN, 2004), estruturado no sentido de identificar os fatores impulsionadores, bem como os fatores restritivos que incentivam ou limitam a intercooperção no contexto investigado.

Para tanto, foram realizadas entrevistas com onze profissionais diretamente envolvidos com a rede: (i) o Presidente da Fundação ABC Pesquisa e Desenvolvimento Agropecuário; (ii) o Diretor Presidente do Conselho de Administração, o Diretor Superintendente e o Gerente Financeiro da Cooperativa A; (iii) o Diretor Presidente do Conselho de Administração e o Diretor Secretário do Conselho de Administração da Cooperativa B; e (iv) o Diretor Presidente do Conselho de Administração, o Superintendente de Operações, o Gerente Corporativo, o Gerente das Unidades de Negócio e o Diretor Financeiro da Cooperativa $\mathrm{C}$.

É importante destacar que foram realizadas mais três entrevistas, uma com o Diretor Presidente do Conselho de Administração e duas entrevistas com o Diretor Financeiro da Cooperativa C, com a finalidade de esclarecimento de dúvidas ocorridas em entrevistas anteriores. $\mathrm{Na}$ fase confirmatória da pesquisa (ou de triangulação dos dados), foi realizada mais uma entrevista com o Diretor Presidente do Conselho de Administração da Cooperativa B. 
Em acréscimo, foi realizada uma observação neutra em reuniões técnicas da rede, conforme orienta Yin (2014), que destaca como pontos fortes desta técnica de coleta de evidências do estudo de caso a cobertura de eventos da realidade em tempo real para uma maior contextualização e a coleta de evidências adicionais, permitindo um maior discernimento sobre o comportamento e os objetivos interpessoais dos agentes envolvidos no estudo.

Os dados coletados foram gravados em meio eletrônico e transcritos para facilitar o processo de análise dos resultados (RIBEIRO; MILAN, 2004; BERNARD; RYAN, 2010) e, então, submetidos à análise de conteúdo, conforme os pressupostos sugeridos (BARDIN, 2011), com auxílio do software NVivo, seguindo-se as recomendações (EDHLUND; MCDOUGALL, 2013), em essência, para identificar os fatores impulsionadores e os fatores restritivos da intercooperação na rede estudada.

\section{RESULTADOS E DISCUSSÃO}

A cooperativa A foi fundada por descendentes de holandeses, alguns imigrantes e outros que vieram de Castro (PR), em 1960. Em 1995, enfrentou uma crise e seus associados decidiram profissionalizar a gestão. Os dirigentes cooperados se afastaram da cooperativa e gestores profissionais, bem remunerados, mas sem participação noslucros, assumiram o comando dos negócios. Os dirigentes cooperados eleitos eram envolvidos na governança, mas ficavam em seus estabelecimentos rurais, cuidando de suas propriedades, apenas vindo à cooperativa quando havia necessidade de assinatura de documentos e/ou nas reuniões ordinárias quinzenais. Nestas reuniões, eram discutidas questões mais amplas, tais como compra de terras, investimentos em indústrias e admissão de novos sócios. Porém, os cooperados eram providos de informações pelos gestores profissionais para tomar suas decisões.

O faturamento da cooperativa cresceu, passando de $\mathrm{R} \$ 94$ milhões em 1995, para $\mathrm{R} \$ 770$ milhões em 2002. O principal bem da cooperativa, sua área agrícola, é de total posse dos cooperados, os quais recebem assistência técnica, insumos e a garantia de recebimento da produção e da comercialização. A cooperativa não compra a produção dos associados, mas presta serviços de recepção e de comercialização. Uma vez que a cooperativa presta serviço ao produtor, cobrando dele para receber, 
beneficiar e industrializar sua matéria-prima, cabe ao produtor decidir sobre quando e para quem vender seus produtos, a partir das informações que recebe sistematicamente sobre as opções de venda ao mercado.

Dessa forma, a Cooperativa A e a rede não correm os riscos das oscilações de mercado. Para isso, contam com três superintendentes que, junto com os cargos eleitos do Conselho Administrativo (Presidente, Vice-presidente e Secretário), fazem sua gestão. Subordinados aos superintendentes, os Comitês Setoriais cuidam das diversas áreas e negócios da cooperativa, incluindo leite, suínos, trigo e outros. As decisões são tomadas nas alçadas dos superintendentes e dos Diretores de Comitês. Apenas assuntos mais complexos são levados para as Assembleias.

Em 1995, todas as cooperativas comercializavam sua produção por meio de uma central com a marca Batavo. Na época, foi decidido vender parte da central para a Parmalat, juntamente com a marca Batavo. Contudo, a experiência de trazer investidores para as indústrias não foi positiva. Reconheceram que os interesses dos investidores eram contrários aos dos produtores cooperados. Por isso, a parceria não deu certo e foi vendida toda a parte industrial, inclusive, com a marca. Posteriormente, a Parmalat vendeu seus ativos para a Perdigão, inclusive as ações que eram da central. As três cooperativas se afastaram da industrialização para voltar sua atenção para outros focos. No entanto, as cooperativas mantiveram o domínio da produção de leite, tanto na questão de genética, como de fomento, controlando o pool de leite.

Embora dominassem o pool de leite, as cooperativas não conseguiam agregar valor à matéria-prima. Buscando resolver a questão, a Cooperativa $\mathrm{C}$ construiu uma indústria de leite própria. Em seguida, a Cooperativa B começou sua própria indústria de leite. Ambas resolveram se unir e repartiram entre si as duas indústrias, para não haver disputa pelo pool do leite. Na oportunidade, a Cooperativa $\mathrm{C}$ passou a fazer parte do negócio, recebendo uma parte das duas indústrias nas suas plantas, gerando escala de produção. No contexto anterior, a produção era vendida para a indústria montada pelas Cooperativas $\mathrm{B}$ e $\mathrm{C}$ e a Cooperativa A apenas fornecia o leite. As capitalizações foram feitas com o suporte financeiro das cooperativas e associados, em ambos os casos (Cooperativas B e C). Dessa forma, as cooperativas aportaram $55 \%$ dos valores de integralização e os cooperados os $45 \%$ restantes. Lucros 
e investimentos obedeciam a proporção de $40 \%$ e $60 \%$, sendo que a cooperativa que detinha $40 \%$ em uma planta deteria $60 \%$ na outra.

Com a entrada da Cooperativa A na rede, esta ficou com 10\% das ações nas duas plantas. Três anos depois apareceram os resultados. As cooperativas puderam pagar para os cooperados um $13^{\circ}$ pagamento sobre a média das entregas de leite anuais, fora a pro rata. O valor era pago a todos os que entregavam leite nas plantas, até cooperados de outras cooperativas que não faziam parte do controle acionário. A diferença é que os cooperados das Cooperativas A, B e C recebiam ainda apro rata ( $10 \%$ sobre capital investido e $90 \%$ sobre volume de produção de leite entregue).

$\mathrm{Na}$ rede informal que se formou, as indústrias de leite são geridas pelas Cooperativas $\mathrm{BeC}$, por serem acionistas majoritárias. A Cooperativa A apenas entrega a sua produção e as Cooperativas $\mathrm{B}$ e $\mathrm{C}$ fazem a gestão como forma de prestação de serviços para as demais da rede, que as remuneram pelo serviço. Assim, evitam custos típicos de operação e gestão de uma central. As cooperativas detectaram que poderiam ser mais eficientes do que uma central, havendo transparência e participação das outras na gestão e governança de cada uma delas. Além da questão financeira, a união das cooperativas trouxe ganhos em relação à sanidade animal, ambiental e nos índices técnicos, agregando mais tecnologia no campo.

A Cooperativa $C$ presta serviços de gestão de forma facultativa para seus associados. Por exemplo, faz o controle contábil dos empreendimentos dos cooperados e presta assessoria tributária, fiscal e jurídica. Além disso, terceiriza a comercialização dos produtos com marcas fortes, tais como Nestlé e Danone, o que contribui para economias de escala, aumento da capacidade de produção e redução dos custos da rede. A parceria com marcas fortes foi indicada por estudos de mercado realizados por empresas de consultoria especializadas, os quais elencaram quais seriam as marcas que mais se enquadrariam ao perfil de qualidade dos produtos das cooperativas da rede.

Outra forma de agregar valor é pelo compartilhamento de áreas-meio, como tecnologia da informação e de produção (esta última fornecida pela Fundação ABC). Parte-se do princípio de que os produtores de qualquer uma das três cooperativas têm as mesmas necessidades. Apesar de se tratar de cooperativas formadas por imigrantes e por descendentes de holandeses, florescem diferenças 
culturais, dentre elas, algumas mal resolvidas no passado e que voltam à tona, como, por exemplo, as questões atinentes ao pool de leite e à expansão geográfica na área de atuação das cooperativas.

Como vantagem competitiva da rede, menciona-se o aumento do poder de barganha junto aos clientes e aos fornecedores e a redução de custos, por haver uma gestão única e integrada. Com estes aspectos, foi possível ofertar um portfólio de produtos melhor para os clientes (leite condensado, leite longa vida, leite em embalagem de $200 \mathrm{~g}$ ). Tal portfólio, que pode ser ofertado a partir da intercooperação, é maior do que seria o portfólio de produtos ofertados individualmente, com própria fábrica da cooperativa atuando separadamente.

A partir do momento em que as cooperativas construíram as indústrias, a confiança dos cooperados na cadeia de comercialização aumentou, ampliando, consequentemente, os investimentos. A intercooperação está na indústria, mas ainda não está totalmente presente no campo. Como as atividades específicas das cooperativas favorecem muito o resultado da intercooperação, os produtores têm de se enquadrar aos padrões de qualidade e às normas técnicas que regem os cooperados das cooperativas, gerando benefícios a todos os partícipes da rede. Atualmente, graças às ações conjuntas das cooperativas, os produtores de leite cooperados têm uma média de produção de leite por vaca maior do que as observadas na Holanda. Os cooperados avaliam tal parâmetro com muito orgulho, pois a região foi colonizada por holandeses que trouxeram consigo como vantagens competitivas um rebanho de vacas holandesas para criação e técnicos para o treinamento dos imigrantes que aqui chegaram.

Isto posto, os resultados da pesquisa apontam que há vários fatores impulsionadores, que contribuem positivamente; ou mesmo fatores restritivos, que contribuem negativamente, para a intercooperação na rede estudada e para o desempenho de seus parceiros de negócio, conforme apresentados no Quadro 1. 
Quadro 1. Fatores impulsionadores e restritivos à intercooperação na rede em estudo

\begin{tabular}{|c|c|c|}
\hline Aspectos Evidenciados & Fatores Impulsionadores & Fatores Restritivos \\
\hline $\begin{array}{l}\text { Criação de Possíveis Van- } \\
\text { tagens Competitivas }\end{array}$ & $\begin{array}{l}\text { - Prestação de serviços de recebimento, de } \\
\text { beneficiamento e de industrialização da } \\
\text { matéria-prima } \\
\text { - Marca forte de parceiros } \\
\text { - Economia de escala } \\
\text { - Redução de custos }\end{array}$ & $\begin{array}{l}\text { - Ausência de marca ou marca pró- } \\
\text { pria fraca } \\
\text { - Produtos industrializados com } \\
\text { pouco valor agregado ou não } \\
\text { industrializados } \\
\text { - Parcerias equivocadas }\end{array}$ \\
\hline Governança e Gestão & $\begin{array}{l}\text { - Tomada de decisão colegiada } \\
\text { - Coparticipação societária } \\
\text { - Mecanismos formais de governança } \\
\text { - Unidades de negócios independentes } \\
\text { - Gestão profissionalizada }\end{array}$ & $\begin{array}{l}\text { - Ausência de mecanismos de presta- } \\
\text { ção de contas conjuntas }\end{array}$ \\
\hline $\begin{array}{c}\text { Reputação e } \\
\text { Comportamento }\end{array}$ & $\begin{array}{l}\text { - Cultura organizacional de qualidade e de } \\
\text { sustentabilidade } \\
\text { - Atendimento às normas, regulamentos e } \\
\text { legislação setoriais } \\
\text { - Nível de exigência das cooperativas em } \\
\text { relação aos cooperados }\end{array}$ & - Concorrência entre cooperativas \\
\hline $\begin{array}{l}\text { Evolução e Desenvolvi- } \\
\text { mento da Rede }\end{array}$ & - Não identificados na rede & $\begin{array}{l}\text { - Resistência à mudança } \\
\text { - Jogos de poder } \\
\text { - Culturas organizacionais diferentes }\end{array}$ \\
\hline $\begin{array}{l}\text { Estratégias de Coope- } \\
\text { ração }\end{array}$ & - Comercialização centralizada & - Falta de visão de mercado \\
\hline $\begin{array}{l}\text { Internacionalização } \\
\text { de Cooperativas }\end{array}$ & $\begin{array}{l}\text { - Parceria com empresas internacionais } \\
\text { renomadas } \\
\text { - Internacionalização através da rede }\end{array}$ & $\begin{array}{l}\text { - Ausência de projeto próprio de } \\
\text { internacionalização }\end{array}$ \\
\hline
\end{tabular}

Além disso, cabe ressaltar que as decisões sobre intercooperação são amplamente discutidas com os membros da Diretoria e os executivos da rede, depois com os cooperados, e finalmente aprovadas em Assembleia. A gestão das cooperativas é de competência dos seus diretores (Presidente, Vice-presidente e superintendente). Normas e regras são definidas e alinhadas pelo conjunto das cooperativas participantes da rede, por meio dos Presidentes dos Conselhos Administrativos. No caso do leite, existem regiões determinadas para a atuação das cooperativas. Por exemplo, a Cooperativa $\mathrm{C}$, que tem a indústria, capta leite in 
natura, fornecendo para as indústrias com marcas fortes.

As decisões mais importantes são tomadas pelos três Presidentes em conjunto. Há ainda, em cada unidade de indústria, um comitê com representantes de todas as cooperativas para gerenciar o seu dia a dia. No entanto, no caso da rede, não existe personalidade jurídica própria para a intercooperação. Cada unidade de negócio industrial está sob a gestão de uma das cooperativas. Nos balanços contábeis padronizados, os resultados são lançados para cada cooperativa, mas entende-se que a intercooperação ocorre como se houvesse uma entidade jurídica única. Mesmo que os balanços contábeis não reflitam a unidade, uma auditoria independente avaliza as informações com vistas à transparência das operações.

Assembleias semestrais, das quais participam representantes de todas as cooperativas, são realizadas para avaliar os resultados. A primeira Assembleia, no meio do ano, avalia a situação de cada cooperativa. Já a Assembleia de final de ano analisa a prestação de contas e aprova ações para o ano seguinte, por votação. Dentre as Assembleias de final de ano, ocorrem pré-assembleias que servem para discussão e para apreciação de temas que serão levados às Assembleias. Existem ainda os Conselhos Deliberativo e Fiscal. Além do Presidente, do Vice-presidente e do Secretário dos Conselhos de Administração, Conselho Fiscal e Conselho Deliberativo, a Cooperativa C conta com mais dois diretores profissionais, um administrativo e outro financeiro, que coordenam as Superintendências de Operações das intercooperações industriais, tanto para o leite, quanto para os suínos, e, futuramente, para o trigo.

Outro assunto relevante envolve os direitos de propriedade entre as cooperativas, os quais são acordados por contratos de longo prazo, da mesma forma que as cooperativas realizam com seus cooperados. A líder no caso da indústria láctea é a Cooperativa $\mathrm{C}$, porque tem maior ativo imobilizado e detém o CNPJ da empresa que industrializa, e assim detém o maior controle acionário ou maior participação. Além disso, tem 54\% de participação no negócio de Unidades de Beneficiamento de Leite (UBLs) em determinada planta, enquanto que a B tem 36\%, e a A tem 10\% de participação no negócio.

Segundo os gestores e cooperados, a despeito dos vários mecanismos de controle e transparência, o processo de gestão é uma experiência que ainda necessita amadurecer. Trata-se de um processo dinâmico, que vai se alterando ao 
longo do tempo. Como a Cooperativa $\mathrm{C}$ tem a gestão de duas unidades de negócio de leite e de carnes, foram criados os cargos de gerente industrial e diretor industrial. Cabe ao Diretor Industrial a gestão destas duas unidades de negócio, respondendo concomitantemente para as Cooperativas A, B e C.

As três cooperativas têm um conselho formado por sete pessoas (três Presidentes, Vice-presidente e Secretário, denominados de Diretoria Executiva), e que são produtores eleitos. Na realidade, não são executivos, mas fazem parte da Diretoria Executiva que acompanha o dia a dia da cooperativa e das unidades de negócio. Duas pessoas desta diretoria participam da direção da unidade de negócios do leite, na qual as três fazem parte. Outras duas pessoas fazem parte da Diretoria da Unidade de Negócios de Carnes e duas pessoas fazem parte da Unidade de Negócio de Trigo.

Para cada Unidade de Negócio, é contratado um gestor que responde para o diretor industrial que, com mais três gestores das três cooperativas com suas diretorias executivas, constituem uma diretoria que define as estratégias da unidade de negócio e cuida da governança. Dessa forma, definem-se as metas e os rumos para a unidade de negócios, por meio de planejamento estratégico. O gestor da Unidade de Negócio tem o acompanhamento de uma diretoria. Os seis cooperados que atuam na diretoria constituem um Conselho Consultivo para o gestor da Unidade de Negócio.

Um Conselho Estratégico, composto pelos membros dos Comitês, do Conselho de Administração, do Conselho Fiscal e os gestores de cada cooperativa, com aproximadamente 50 pessoas, avalia as implementações de novos projetos e o andamento do planejamento estratégico das unidades de negócios. O grupo se reúne uma ou duas vezes por ano para realinhar as estratégias das cooperativas e trocar informações de modo que uma conheça as estratégias da outra. Assim se intensifica o poder de intercooperação entre as unidades de negócio pela troca de ideias e de experiências. As unidades de negócio têm um programa de auditorias internas, que são disponibilizadas ao Conselho de Administração. As auditorias são programadas e visam buscar ações preventivas.

A Fundação ABC, por sua vez, abarca uma estrutura de Assembleias, de Conselho Fiscal, de Conselho Curador, de Diretoria Executiva, de Conselho Técnico- 
Científico e de Gerência Geral, que funciona semelhantemente às cooperativas, com o detalhe de que não distribui lucros no final do ano. Trata-se de uma instituição de utilidade pública federal, estadual e municipal que tem algumas vantagens fiscais, por ser sem fins lucrativos.

As Assembleias da Fundação $\mathrm{ABC}$ são constituídas pelos membros das diretorias das três cooperativas e mais alguns sócios indicados pelas demais participantes. A Presidência da Fundação $A B C$ é exercida de modo rotativo entre as cooperativas, que se sucedem no cargo. Os direitos de cada cooperativa são resguardados por contratos formais assinados entre as cooperativas, com média de validade de dez anos. Muitos desses contratos possuem a prorrogação automática dos prazos vigentes. A estrutura de poder da Fundação ABC é baseada no entendimento dos presidentes das cooperativas que se reúnem periodicamente para tratar da governança e dos interesses comuns.

A questão da governança da rede é exercida pelos três Presidentes das Cooperativas, que são membros natos dos Conselhos de Administração dos Frigoríficos. No caso da Cooperativa $\mathrm{C}$, quem exerce a função é o superintendente contratado especificamente por ser um profissional da área, não sendo sócio da cooperativa. As três cooperativas gozam de excelente imagem no mercado tanto para com as pessoas de fora, como entre elas.

Uma das exigências para a parceria entre as cooperativas seria que cada uma tivesse matéria-prima de qualidade e produção convenientemente organizada. Por exemplo, no caso do leite, é essencial o controle de sanidade com o acompanhamento intenso e contínuo dos produtores, técnica e economicamente, principalmente com foco em resultados para os produtores cooperados, e não apenas em resultados para a cooperativa.

A intercooperação se ressalta pela similaridade entre as cooperativas, ou seja, não pelo fato de serem provenientes de descendentes de holandeses, mas sim pela maneira de ser cooperativa, a visão sistêmica, a qual se mostra, por exemplo, na relação firme com seus associados, que exigem o cumprimento dos contratos firmados, o cumprimento da qualidade exigida e a entrega dos produtos para as cooperativas a que pertencem. Os produtores que não cumprem os contratos são considerados cooperados não integrados, o que reduz os serviços que poderão 
usufruir e, em muitos casos, são excluídos do quadro de cooperados. Tais regras são bem claras nos contratos que são assinados entre as Cooperativas e seus associados.

A intercooperação ocorre por três distintas razões: doutrinária, de afinidade e política. Quando se olha para as origens, surge a confiança que todos têm em cada diretoria, que cada membro de cada cooperativa deposita no outro. Ou seja, as cooperativas, para intercooperar, são impulsionadas por razões de mercado. A ideia é evitar disputas de mercado e ainda ganhar escala ou, em outras palavras, uma das principais causas que leva as cooperativas a cooperar entre si é a perspectiva de lucro maior, de conquista de melhor resultado para cada segmento da cadeia.

Por outro lado, não foi verificada a intenção de internacionalização das cooperativas em separado, mas da rede como um todo, especialmente no segmento de suínos. Assume-se que as questões de internacionalização sejam mais convenientemente conduzidas via rede. Há parceiros internacionais que querem entrar no mercado brasileiro e que estão interessados em matéria-prima de qualidade, o que viabilizaria tanto sua entrada no Brasil, como a internacionalização dos produtos das cooperativas com as marcas internacionais. Para tanto, cumpre organizar as questões que tangem à produção e à matéria-prima. Atualmente, não há um processo de internacionalização de modo abrangente, e o assunto é tratado por setor, especialmente para aqueles que já estão preparados para as operações.

A pesquisa assinalou que a ausência de uma marca própria da rede dificulta a comercialização dos produtos dos cooperados. Dessa forma, houve a necessidade de promover parcerias com empresas internacionais com marcas renomadas para fazer frente às dificuldades que surgiriam ao se tentar criar uma marca própria forte. Cabe mencionar que diferenças culturais significativas geram bairrismo que, às vezes, acarreta a construção de interesses diferentes, o que pode prejudicar a intercooperação. Algumas unidades, especialmente aquelas nas quais não há industrialização, como a Unidade de Batatas da Cooperativa C, ainda têm algumas restrições no que se refere à intercooperação.

O que ainda não existe na rede, e poderia ser desenvolvido, seria trabalhar com produtos de maior valor agregado, pois as cooperativas operam com produtos que não têm valor agregado significativo. As indústrias de leite poderiam procurar alternativas pelas quais pudessem ter percepção maior de valor no produto e 
buscar desenvolver produtos e mercados que identifiquem a qualidade do leite que a cooperativa comercializa como maior valor agregado, por exemplo, através de benchmarking.

Em 1998, as cooperativas julgaram que a central era pequena demais para competir em nível nacional e grande demais para o âmbito regional. Então, criaram uma nova cooperativa com o nome de Batávia S. A., propriedade das cooperativas que estavam na central. A Batávia era composta em $51 \%$ de uma empresa internacional e $49 \%$ das cooperativas da central, que venderam a indústria de carnes da central (que se tornou propriedade da Batávia) com uma terceira indústria de grande porte nacional e que, ano e meio depois, assumiu também os $49 \%$ que pertenciam à Batávia. Na época, as cooperativas saíram do ramo de suínos e de aves e ficaram apenas com o segmento do leite, porém se atingiram pela crise que acometeu a empresa parceira internacional e tentaram levar o negócio adiante. Após uma grande ação judicial, a empresa nacional, que já havia ficado com os frigoríficos, comprou as ações da empresa internacional, passando a ser majoritária da Batávia nas questões do leite, ao deter $51 \%$ das ações. Depois de certo tempo, as cooperativas decidiram vender sua parte na indústria do leite para a empresa nacional que detinha as açóes majoritárias, que ficou com a marca Batavo, não se interessando pela marca da Cooperativa C. A respeito disso, existia uma disputa velada pelo poder. Assim seriam criados feudos formados não apenas por pessoas, mas por grupos que dificultavam a questão da fusão, mesmo com uma consultoria vinda da Holanda para fazer o estudo para que a fusão acontecesse.

O modelo de intercooperação da rede foi fruto de uma decisão colegiada. No entanto, cada cooperativa tem poder de voto proporcional à sua participação no negócio. Duas delas (as Cooperativas B e C), que têm mais capital, possuem maior poder decisório que a terceira. Como as duas com mais poder decisório podem tomar ações equivocadas, isso dificulta que as três consigam formar consenso. Ainda não existe uma Assembleia Geral Ordinária das três juntas para se discutir a intercooperação e a apresentação dos números, de forma conjunta. Em algumas cooperativas, não existe conselho de ética e consultivo.

Os problemas que se apresentam na governança conjunta recaem sempre no ser humano, nas vaidades pessoais e nas questões pessoais que, muitas 
vezes, influenciam negativamente o bom andamento da estrutura. Entretanto, as cooperativas que entregam o leite de seus produtores para a industrialização nas unidades de negócio manifestaram interesse em fazer parte acionária das unidades. Porém, como houve investimento alto no setor, teriam de se capitalizar para entrar como acionistas, o que inviabiliza a empreitada. Outrossim, as três cooperativas não desejaram abrir a posição acionária das Unidades de Negócio.

\section{CONSIDERAÇÕES FINAIS}

Em se tratando da criação de vantagens competitivas, as cooperativas agroalimentares atuando em rede horizontal apresentam fatores impulsionadores à intercooperação pelo fato de a rede se valer de marcas fortes de empresas internacionais parceiras, prestarem serviços além da comercialização centralizada e propiciar economia de escala e redução de custos. Em contrapartida, a intercooperação entre as cooperativas fica prejudicada pela comercialização de produtos industrializados com pouco valor agregado, pela realização de algumas parcerias equivocadas e ausência de marca própria forte.

No que diz respeito à governança e à gestão da rede, a análise dos dados mostra que há mecanismos impulsionadores que contribuem positivamente para a cooperação entre as cooperativas associadas, dentre eles, os mecanismos formais de governança para a prestação de contas e que propicia a tomada de decisões colegiadas, a organização de uma equipe de gestão profissionalizada, a coparticipação acionária de cada cooperativa nas outras e a presença de unidades de negócios que são geridas de forma independente. Por outro lado, a ausência de mecanismos formais para a prestação conjunta de contas se revela como principal fator restritivo à intercooperação na rede.

Quanto à reputação e ao comportamento das cooperativas e dos associados em relação à rede, percebe-se que a imagem positiva no mercado decorre da cultura organizacional de qualidade, da sustentabilidade, do atendimento às normas, aos regulamentos e à legislação setorial e do alto nível de exigência das cooperativas em relação ao acordado com seus cooperados. Todavia, a intercooperação pode ser prejudicada por casos de concorrência entre as cooperativas. 
Do ponto de vista da evolução e do desempenho da cooperação, os gestores da rede não destacaram nenhum fator impulsionador específico à intercooperação na rede, mas atentaram para os fatores restritivos, tais como jogos de poder, resistência à mudança e culturas organizacionais muito diferentes entre as cooperativas no âmbito da rede. Sobre as estratégias de cooperação, os respondentes destacam principalmente a comercialização centralizada como fator impulsionador da intercooperação, o que pode, porém, ser prejudicado pela falta de visão de mercado de alguns gestores de cooperativas partícipes da rede.

Consoante a isso, o estudo contribui com o levantamento de fatores impulsionadores e fatores restritivos à intercooperação em uma rede de cooperativas ligadas à cadeia do leite do Estado do Paraná, uma das mais representativas do país, bem como a descrição de como os parceiros de negócios (membros da rede) procedem em relação à governança ou à gestão da mesma. Com base em um estudo de uma realidade no contexto brasileiro, espera-se ter contribuído, ainda, com a discussão sobre as dificuldades e os resultados provenientes da intercooperação, principalmente ao se levar em consideração o ambiente do agronegócio no Brasil, caracterizado pela marcante presença de empresas de micro, pequeno e médio porte, com forte presença familiar.

Acerca das limitações da pesquisa, alguns aspectos merecem ser destacados. A coleta de dados poderia ter envolvido um número maior de entrevistados em cada uma das Cooperativas ou na própria Fundação das Cooperativas, bem como conduzir as entrevistas em duas sessões, o que possibilitaria uma melhor verificação da consistência dos dados coletados. Também poderia ter sido oportuno o levantamento de dados tais como faturamento anual bruto, lucro e rentabilidade, embora haja relativa dificuldade dos gestores disponibilizarem dados desta natureza.

Como possibilidade para estudos futuros seria interessante o desenvolvimento de pesquisas, tanto com abordagem qualitativa quanto quantitativa, que contemplassem construtos como, por exemplo, a confiança e o compromisso entre os parceiros envolvidos. Também poderia ser investigada a verificação da incidência ou da efetividade das táticas vinculantes (sociais, estruturais e financeiras) como recursos para o fortalecimento dos relacionamentos existentes. Além disso, seria oportuno pesquisar aspectos tais como a força da(s) marca(s) da rede ou 
dos seus membros, sua imagem de mercado e a relevância da reputação e da credibilidade gerada pela intercooperação no sentido de ampliação do espaço de mercado ocupado pelas redes em comparação a redes concorrentes.

\section{AGRADECIMENTO}

Os autores do artigo agradecem aos avaliadores $A d H o c$ da Revista, com base em um processo blinded review, pelas sugestões de melhorias que possibilitaram a qualificação do trabalho.

\section{REFERÊNCIAS}

ALBERS, S. The design of alliance governance systems. Köln: Kölner Wissenschaftsverlag, 2005.

ANDRADE, A.; ROSSETTTI, J. P. Governança corporativa: fundamentos, desenvolvimento e tendências. 4. ed. São Paulo: Atlas, 2009.

BALESTRIN, A.; VERSCHOORE, J. Redes de cooperação empresarial: estratégia de gestão na nova economia. 2. ed. Porto Alegre: Bookman, 2016.

BARDIN, L. Análise de conteúdo. São Paulo: Edições 70, 2011.

BERNARD, H. R.; RYAN, G. W. Analyzing qualitative data: systematic approaches. Thousand Oaks: Sage Publications, 2010.

BIALOSKORSKI NETO, S. Economics and management of cooperatives organizations. Berlin: Germany Saarbrücken, 2016.

CARVALHO, A. D. O cooperativismo sob a ótica da gestão estratégica global. São Paulo: Baraúna, 2011.

CRÚZIO, H. O. Como organizar e administrar uma cooperativa. Rio de Janeiro: Editora FGV, 2005.

DAVIS, P.; BIALOSKORSKI NETO, S. Governança e gestão de capital social em coo- 
perativas: uma abordagem baseada em valores. Economia Solidária e Ação Cooperativa, v. 5, n. 1, p. 1-24, 2010.

EDHLUND, B. M.; MCDOUGALL, A. G. NVivo 11 essentials. Stallarholmen: Form \& Kunskap AB, 2013.

HAGE, J.; ALTER, C. A typology of interorganizational relationships and networks. In: HOLLINGSWORTH, J. R.; BOYER, R. (ed.). Contemporary capitalism: the embeddedness of institutions. Cambridge: Cambridge University Press, 1997. p. 94-126.

IBGE. Indicadores IBGE: estatística da produção pecuária 2016. Brasília: IBGE, 2016.

LAGO, A.; SILVA, T. N. Fatores condicionantes do desenvolvimento de relacionamento intercooperativos no cooperativismo agropecuário. Porto Alegre: SESCOOP-RS, 2011.

LECHAT, N. M. P. As raízes históricas da economia solidária e seu aparecimento no Brasil. In: SINGER, P. (org.). Economia solidária. Rio de Janeiro: Universidade Federal Fluminense, 2008. v. 2.

LEITE, J. S. Cooperação e intercooperação. Lisboa: Livros Horizonte, 1982.

MARTI, E. M.; IGUAL, J. F. La intercoperación: una respuesta a las actuales demandas del cooperativismo agrario. Estudios de Economía Aplicada, n. 26, p. 57-88, abr. 2008.

MENDINA, H. J. C. Proposta de framework para intercooperação entre cooperativas agroalimentares atuando em rede horizontal. 2015. $283 \mathrm{f}$. Tese (Doutorado em Administração) - Universidade do Vale do Rio dos Sinos, São Leopoldo, SC, 2015.

MITCHELL, T. R. An evolution of the validity of correlational research conducted in organizations. Academy of Management Review, v. 10, n. 2, p. 192-205, 1985.

MORAIS, E. E.; LANZA, F. Cooperativismo e economia solidária: capitalismo refor- 
mado ou alternativas socioeconômicas. In: SIMPÓSIO LUTAS SOCIAIS NA AMÉRICA LATINA, 4., 2010, Londrina. Anais [...]. Londrina: Universidade Estadual de Londrina, 2010.

MORAIS, E. E.; LANZA, F.; SANTOS, L. M. L.; PELANDA, S. S. Propriedades coletivas, cooperativismo e economia solidária no Brasil. Serviço Social \& Sociedade, n. 105, p. 67-88, jan./mar. 2011.

PALACIO, J. R. S.; CLIMENT, V. C. La dirección estratégica en la economía social: utilización de herramientas de análisis estratégico en las cooperativas. Revista de Economía Pública, Social y Cooperativa, v. 59, p. 237-258, 2007.

PARK, S. H.; UNGSON,G. R. Interfirm rivalry and managerial complexity: a conceptual framework of alliance failure. Organization Science, v. 12, n. 1, p. 37-53, 2001.

PEDROSA ORTEGA, C.; HERNÁNDEZ ORTIZ, M. J. Como aplican las sociedades cooperativas de éxito los principios cooperativos? El caso del Grupo Hojiblanca. Revista de Economía Pública, Social y Cooperativa, n. 72, p. 157-185, out. 2011.

PIORE, M. J.; SABEL, C. F. The second industrial divide. New York: Basic Books, 1984.

PORTER, M. E. Vantagem competitiva: criando e sustentando um desempenho superior. Rio de Janeiro: Campus, 1990.

PROVAN, K.; KENIS, P. Modes of network governance: structure, management, and effectiveness. Journal of Public Administration Research and Theory, v. 18, n. 2, p. 229-252, 2007.

PYKE, P.; SENGENBERGER, W. (ed.). Industrial districts and local economic regeneration. Geneva: International Institute for Labour Studies, 1992.

REMLER, D. K.; VAN RYZIN, G. G. Research methods in practice: strategies for description and causation. Thousand Oaks: Sage Publications, 2011. 
RIBEIRO, J. L. D.; MILAN, G. S. Planejando e conduzindo entrevistas individuais. In: RIBEIRO, J. L. D.; MILAN, G. S. (ed.). Entrevistas individuais. Porto Alegre: FEEng/ UFRGS, 2004. cap. 1, p. 9-22.

SCHNEIDER, J. O. (coord.). Educação e capacitação cooperativa: os desafios no seu desempenho. São Leopoldo: Unisinos, 2010.

TODEVA, E. Business networks: strategy and structure. London: Routledge, 2006.

TRIGUERO-CANO, A.; CUERVA NARRO, M. C. C. El cooperativismo agroalimentario ante el reto de la globalización: "renovar-se o morir". Revista de Economía Pública, Social y Cooperativa, n. 72, p. 97-124, 2011.

VENKATRAMAN, N.; CHI-HYON, L. Preferential linkage and network evolution: a conceptual model and empirical test in the U.S. vídeo game sector. The Academy of Management Journal, v. 47, n. 6, p. 876-892, 2004.

WEGNER, D.; PADULA, A. D. Estratégias de crescimento e a governança de redes horizontais de empresas: o caso da maior rede cooperativa de varejo de alimentos na Alemanha. Revista de Ciências da Administração, v. 13, n. 30, p. 220-248, 2011.

WILLIAMSON, O. Calculativeness, trust and economic organization. Journal of Law and Economics, v. 36, n. 2, p. 453-486, 1993.

WILLIAMSON, O. The economic institutions of capitalism. New York: Free Press, 1985.

YIN, R. K. Case study research: design and methods. $5^{\text {th }}$ ed. Thousand Oaks: Sage Publications, 2014.

Recebido em: 30/07/2017

Aceito em: 29/08/2018 